\title{
Managing Revenue Risk of the Firm: Commodity Futures and Options *
}

\author{
Udo Broll ${ }^{\dagger}$ \\ Dresden University of Technology \\ Kit Pong Wong $\ddagger$ \\ University of Hong Kong
}

July 2015

\begin{abstract}
This paper examines the behavior of the competitive firm that faces not only output price uncertainty but also a revenue shock. The firm can trade fairly priced futures and put option contracts for hedging purposes. We show that neither the separation theorem nor the full-hedging theorem holds when the revenue shock prevails. The correlation between the random output price and the revenue shock plays a pivotal role in determining the firm's optimal production and hedging decisions. If the correlation is non-positive, the firm's optimal output level is smaller than that without the revenue shock. Furthermore, the firm's optimal hedge position consists of an under-hedge and a long put option position if the firm's preferences exhibit prudence. The prevalence of revenue risk as such makes financial and operational hedging act as complements to better cope with multiple sources of uncertainty.
\end{abstract}

JEL classification: D21; D24; D81

Keywords: Financial hedging; Operational hedging; Prudence

\footnotetext{
${ }^{*}$ We would like to thank Rogemar Mamon (the editor), an associate editor, and an anonymous referee for their helpful comments and suggestions. The usual disclaimer applies.

${ }^{\dagger}$ Corresponding author. Department of Business and Economics, School of International Studies (ZIS), Dresden University of Technology, 01062 Dresden, Germany. E-mail: udo.broll@tu-dresden.de (U. Broll).

${ }^{\ddagger}$ School of Economics and Finance, University of Hong Kong, Pokfulam Road, Hong Kong. E-mail: kpwong@econ.hku.hk (K. P. Wong).
} 


\title{
Managing Revenue Risk of the Firm: Commodity Futures and Options
}

\begin{abstract}
This paper examines the behavior of the competitive firm that faces not only output price uncertainty but also a revenue shock. The firm can trade fairly priced futures and put option contracts for hedging purposes. We show that neither the separation theorem nor the full-hedging theorem holds when the revenue shock prevails. The correlation between the random output price and the revenue shock plays a pivotal role in determining the firm's optimal production and hedging decisions. If the correlation is non-positive, the firm's optimal output level is smaller than that without the revenue shock. Furthermore, the firm's optimal hedge position consists of an under-hedge and a long put option position if the firm's preferences exhibit prudence. The prevalence of revenue risk as such makes financial and operational hedging act as complements to better cope with multiple sources of uncertainty.
\end{abstract}

JEL classification: D21; D24; D81

Keywords: Financial hedging; Operational hedging; Prudence

\section{Introduction}

Since the seminal work of Sandmo (1971), the theory of the competitive firm has been the subject of considerable research in decision making under uncertainty (see, e.g., Batra and Ullah, 1974; Broll and Wong, 2013; Chavas, 1985; Viaene and Zilcha, 1998; Wong, 1996; to name just a few). One important strand of this literature is on the behavior of the competitive firm when a commodity futures market exists for hedging purposes (see, e.g., Danthine, 1978; Feder et al., 1980; Holthausen, 1979; Wong, 2014, 2015). Two notable results emerge. First, the separation theorem states that the firm's production decision 
depends neither on its risk attitude nor on the underlying output price uncertainty. Second, the full-hedging theorem states that the firm should completely eliminate its output price risk exposure by adopting a full-hedge should the commodity futures market be unbiased. ${ }^{1}$

An immediate implication of the full-hedging theorem is that no other hedging instruments, options in particular, would have a hedging role that is over and above that of futures, thereby rendering futures to be the most preferred hedging instrument (Battermann et al., 2000). Indeed, Lapan et al. (1991) show that the competitive firm uses options only when it perceives the futures price and/or option premiums as biased. In this regard, options appear more like a speculative device than a hedging instrument.

The purposes of this paper are to examine the robustness of the separation and fullhedging theorems in general, and the hedging role of options in particular, when the competitive firm is also subject to a multiplicative shock to its revenue (Adam-Müller, 1997; Wong, 2013). Such a revenue shock may come from uncertain exchange rates, production uncertainty, credit risk, and many other sources. The revenue shock is allowed to be correlated with the random output price. However, the revenue shock is neither hedgeable nor insurable.

We show that the prevalence of the revenue shock invalidates both the separation and full-hedging theorems. The correlation between the revenue shock and the random output price plays a pivotal role in determining the firm's optimal production and hedging decisions. Specifically, if this correlation is non-positive, we show that the firm's optimal output level is smaller than that without the revenue shock. The firm finds it optimal to produce less in order to limit its risk exposure to the unhedgeable revenue shock. We show further that there is a correlation motive that induces the firm to sell more or less the commodity futures contracts and opt for a short or long put option position, depending on whether the correlation between the revenue shock and the random output price is positive or negative, respectively. In addition, if the firm's preferences satisfy the reasonable property of prudence

\footnotetext{
${ }^{1}$ The full-hedging theorem is analogous to a well-known result in the insurance literature that a risk-averse individual fully insures at an actuarially fair price (Mossin, 1968).
} 
(Kimball, 1990, 1993), there is a precautionary motive that calls for a long futures position and a long put option position. As such, the correlation motive reinforces the precautionary motive should the correlation between the revenue shock and the random output price be non-positive. In this case, the firm's optimal hedge position consists of an under-hedge and a long put option position.

This paper is closely related to Wong (2013) that examines the behavior of an exporting firm facing correlated revenue and exchange rate risk. Like us, Wong (2013) shows that the separation and full-hedging theorems do not hold. Unlike us, Wong (2013) restricts the exporting firm to trade currency futures contracts only for hedging purposes. Indeed, we show that options play a hedging role over and above that of futures when revenue risk prevails. In this sense, we offer a more complete description of how financial and operational hedging should be structured when firms are subject to revenue shocks.

The rest of this paper is organized as follows. Section 2 develops our model of the competitive firm under joint revenue and output price risk. The firm can trade unbiased commodity futures and put option contracts for hedging purposes. Section 3 considers a benchmark case wherein the revenue risk is absent. Section 4 examines the firm's optimal production decision. Section 5 characterizes the firm's optimal hedge position. Section 6 constructs a reasonable example that has a closed-form solution. The final section concludes.

\section{The model}

Consider the competitive firm under output price uncertainty à la Sandmo (1971). There is one period with two dates, 0 and 1 . To begin, the firm produces a single commodity according to a deterministic cost function, $C(Q)$, where $Q \geq 0$ is the output level chosen by the firm at date 0 , and $C(Q)$ is compounded to date 1 . The firm's production technology exhibits decreasing returns to scale so that $C(Q)$ satisfies that $C(0)=C^{\prime}(0)=0$, and that $C^{\prime}(Q)>0$ and $C^{\prime \prime}(Q)>0$ for all $Q>0$. 
At date 1, the firm sells its entire output, $Q$, at the then prevailing per-unit output price, $\tilde{P}$, that is not known ex ante. ${ }^{2}$ Let $F(P):[\underline{P}, \bar{P}] \rightarrow[0,1]$ be the marginal cumulative distribution function $(\mathrm{CDF})$ of $\tilde{P}$, where $0<\underline{P}<\bar{P}$. As in Adam-Müller (1997) and Wong (2013), the firm's revenue at date 1 is subject to a multiplicative shock, $\tilde{\theta}$, which is a positive random variable with unit mean, and is neither hedgeable nor insurable. Let $G(\theta):[\underline{\theta}, \bar{\theta}] \rightarrow[0,1]$ be the marginal CDF of $\tilde{\theta}$, where $0<\underline{\theta}<1<\bar{\theta}$. To allow the possible correlation between $\tilde{\theta}$ and $\tilde{P}$, let $H(\theta, P):[\underline{\theta}, \bar{\theta}] \times[\underline{P}, \bar{P}] \rightarrow[0,1]$ be their joint CDF.

At date 0 , the firm can hedge against its risk exposure to the random output price, $\tilde{P}$, by trading infinitely divisible commodity futures and put option contracts, each of which calls for delivery of one unit of the commodity at date $1 .^{3}$ The futures price is predetermined at $P^{f} \in(\underline{P}, \bar{P})$. The commodity put option contracts have a single strike price, $K \in(\underline{P}, \bar{P})$, and an exogenously given option premium, $\Phi>0$, per contract. ${ }^{4}$ The firm's profit, $\tilde{\Pi}$, at date 1 is, therefore, given by

$$
\tilde{\Pi}=\tilde{\theta} \tilde{P} Q+\left(P^{f}-\tilde{P}\right) X+[\Phi-\max (K-\tilde{P}, 0)] Y-C(Q)
$$

where $X$ and $Y$ are the numbers of the commodity futures and put option contracts sold (purchased if negative) by the firm at date 0 , respectively.

We refer to the pair, $(X, Y)$, as the firm's hedge position. The futures position, $X$, is said to be an under-hedge, a full-hedge, or an over-hedge, depending on whether $X$ is smaller than, equal to, or greater than the output level, $Q$, respectively. On the other hand, the put option position, $Y$, is said to be a long or short position, depending on whether $Y$ is negative or positive, respectively.

\footnotetext{
${ }^{2}$ Throughout the paper, random variables have a tilde $(\sim)$ while their realizations do not.

${ }^{3}$ Because of the put-call parity, one can replicate payoffs of any combinations of futures, calls, and puts by any two of these three financial instruments, thereby rendering one of them to be redundant. Restricting the firm to use only commodity futures and put option contracts is without any loss of generality.

${ }^{4}$ In principle, the strike price, $K$, should also be a choice variable of the firm. If $K$ is very close to $\underline{P}$, the put option contracts would be out of the money almost surely and thus have little use to the firm. On the other hand, if $K$ is very close to $\bar{P}$, the put option contracts would be in the money almost surely and thus are not different from the futures contracts. Hence, if $K$ is a choice variable, the firm should optimally choose $K$ such that the put option contracts are neither too out of the money nor too in the money so as to further improve the hedge effectiveness (Ahn et al., 1999).
} 
The firm possesses a von Neumann-Morgenstern utility function, $U(\Pi)$, defined over its profit, $\Pi$, at date 1 . The firm is risk averse so that $U^{\prime}(\Pi)>0$ and $U^{\prime \prime}(\Pi)<0$ for all $\Pi>0 .{ }^{5}$ The firm's ex-ante decision problem is to choose an output level, $Q \geq 0$, and a hedge position, $(X, Y)$, at date 0 so as to maximize the expected utility of its profit at date 1:

$$
\max _{Q \geq 0, X, Y} \mathrm{E}[U(\tilde{\Pi})]
$$

where $\mathrm{E}(\cdot)$ is the expectation operator with respect to the joint $\operatorname{CDF}, H(\theta, P)$, and $\tilde{\Pi}$ is given by Eq. (1).

The first-order conditions for program (2) are given by

$$
\begin{aligned}
& \mathrm{E}\left\{U^{\prime}\left(\tilde{\Pi}^{*}\right)\left[\tilde{\theta} \tilde{P}-C^{\prime}\left(Q^{*}\right)\right]\right\}=0, \\
& \mathrm{E}\left[U^{\prime}\left(\tilde{\Pi}^{*}\right)\left(P^{f}-\tilde{P}\right)\right]=0,
\end{aligned}
$$

and

$$
\mathrm{E}\left\{U^{\prime}\left(\tilde{\Pi}^{*}\right)[\Phi-\max (K-\tilde{P}, 0)]\right\}=0
$$

where an asterisk $\left(^{*}\right)$ signifies an optimal level. The second-order conditions for program (2) are satisfied given risk aversion and the strict convexity of the cost function.

To focus on the firm's pure hedging motive, we hereafter assume that the commodity futures and put option contracts are fairly priced in that $P^{f}=\mathrm{E}(\tilde{P})$ and $\Phi=\mathrm{E}[\max (K-$ $\tilde{P}, 0)]$. Using the covariance operator, $\operatorname{Cov}(\cdot, \cdot)$, with respect to the joint $\operatorname{CDF}, H(\theta, P)$, we can write Eqs. (3), (4), and (5) as ${ }^{6}$

$$
\mathrm{E}(\tilde{P})+\operatorname{Cov}(\tilde{\theta}, \tilde{P})-C^{\prime}\left(Q^{*}\right)=-\frac{\operatorname{Cov}\left[U^{\prime}\left(\tilde{\Pi}^{*}\right), \tilde{\theta} \tilde{P}\right]}{\mathrm{E}\left[U^{\prime}\left(\tilde{\Pi}^{*}\right)\right]},
$$

\footnotetext{
${ }^{5}$ We can motivate the risk-averse behavior of the firm by managerial risk aversion (Stulz, 1984), corporate taxes (Smith and Stulz, 1985), costs of financial distress (Smith and Stulz, 1985), and/or capital market imperfections (Froot et al., 1993; Stulz, 1990). See Tufano (1996) for evidence that managerial risk aversion is a rationale for corporate risk management in the gold mining industry.

${ }^{6}$ For any two random variables, $\tilde{X}$ and $\tilde{Y}$, we have $\operatorname{Cov}(\tilde{X}, \tilde{Y})=\mathrm{E}(\tilde{X} \tilde{Y})-\mathrm{E}(\tilde{X}) \mathrm{E}(\tilde{Y})$.
} 


$$
\operatorname{Cov}\left[U^{\prime}\left(\tilde{\Pi}^{*}\right), \tilde{P}\right]=0
$$

and

$$
\operatorname{Cov}\left[U^{\prime}\left(\tilde{\Pi}^{*}\right), \max (K-\tilde{P}, 0)\right]=0
$$

respectively, where Eq. (6) takes into account the fact that $\mathrm{E}(\tilde{\theta})=1$.

\section{Benchmark case without revenue risk}

In this section, we consider a benchmark case wherein the revenue shock is absent, i.e., $\tilde{\theta} \equiv 1$. Eqs. (6), (7), and (8) as such become

$$
\begin{aligned}
& \mathrm{E}(\tilde{P})-C^{\prime}\left(Q^{\circ}\right)=-\frac{\operatorname{Cov}\left[U^{\prime}\left(\tilde{\Pi}^{\circ}\right), \tilde{P}\right]}{\mathrm{E}\left[U^{\prime}\left(\tilde{\Pi}^{\circ}\right)\right]}, \\
& \operatorname{Cov}\left[U^{\prime}\left(\tilde{\Pi}^{\circ}\right), \tilde{P}\right]=0,
\end{aligned}
$$

and

$$
\operatorname{Cov}\left[U^{\prime}\left(\tilde{\Pi}^{\circ}\right), \max (K-\tilde{P}, 0)\right]=0
$$

respectively, where a nought $\left(^{\circ}\right)$ signifies an optimal level in this benchmark case, and $\tilde{\Pi}^{\circ}$ is given by Eq. (1) with $\tilde{\theta} \equiv 1$. Solving Eqs. (9), (10), and (11) simultaneously yields our first proposition.

Proposition 1. Given that the commodity futures and put option contracts are fairly priced, and that the revenue shock is absent, the competitive firm's optimal output level, $Q^{\circ}$, is the unique solution to

$$
\mathrm{E}(\tilde{P})=C^{\prime}\left(Q^{\circ}\right)
$$


and its optimal hedge position, $\left(X^{\circ}, Y^{\circ}\right)$, consists of a full-hedge, i.e., $X^{\circ}=Q^{\circ}$, and no options, i.e., $Y^{\circ}=0$.

Proof. Substituting Eq. (10) into Eq. (9) yields Eq. (12). Suppose that $X^{\circ}=Q^{\circ}$ and $Y^{\circ}=0$. The firm's profit at date 1 becomes $\mathrm{E}(\tilde{P}) Q^{\circ}-C\left(Q^{\circ}\right)$, which is non-stochastic. In this case, Eqs. (10) and (11) are satisfied simultaneously, thereby implying that $X^{\circ}=Q^{\circ}$ and $Y^{\circ}=0$ are indeed the firm's optimal hedge position.

To see the intuition for Proposition 1 , we substitute $\tilde{\theta} \equiv 1, P^{f}=\mathrm{E}(\tilde{P})$, and $\Phi=$ $\mathrm{E}[\max (K-\tilde{P}, 0)]$ into Eq. (1) to yield

$$
\begin{aligned}
\tilde{\Pi}= & \mathrm{E}(\tilde{P}) Q-C(Q)+[\tilde{P}-\mathrm{E}(\tilde{P})](Q-X) \\
& +\{\mathrm{E}[\max (K-\tilde{P}, 0)]-\max (K-\tilde{P}, 0)\} Y .
\end{aligned}
$$

Inspection of Eq. (13) reveals that the firm could have completely eliminated its output price risk exposure had it chosen a full-hedge, i.e., $X=Q$, and used no options, i.e., $Y=0$,

within its own discretion. Alternatively put, the degree of output price risk exposure to be assumed by the firm should be totally unrelated to its production decision. The firm as such chooses the optimal output level, $Q^{\circ}$, that maximizes $\mathrm{E}(\tilde{P}) Q-C(Q)$, which gives rise to Eq. (12). Since the commodity futures and put option contracts are fairly priced, the firm finds it optimal to completely eliminate its output price risk exposure by adopting a full-hedge, i.e., $X^{\circ}=Q^{\circ}$, and using no options, i.e., $Y^{\circ}=0$. These results are simply the celebrated separation and full-hedging theorems emanated from the literature on the behavior of the competitive firm under output price uncertainty. In this benchmark case, options play no role as a hedging instrument (Battermann et al., 2000; Lapan et al., 1991).

\section{Optimal production decision}

In this section, we examine the firm's optimal output level, $Q^{*}$, when the revenue risk 
prevails. Since the revenue shock is neither hedgeable nor insurable, the firm's profit at date 1 must be stochastic. Eq. (1) as such implies that

$$
\begin{aligned}
\operatorname{Cov}\left[U^{\prime}\left(\tilde{\Pi}^{*}\right), \tilde{\Pi}^{*}\right] & =\operatorname{Cov}\left[U^{\prime}\left(\tilde{\Pi}^{*}\right), \tilde{\theta} \tilde{P} Q^{*}-\tilde{P} X^{*}-\max (K-\tilde{P}, 0) Y^{*}\right] \\
& =\operatorname{Cov}\left[U^{\prime}\left(\tilde{\Pi}^{*}\right), \tilde{\theta} \tilde{P}\right] Q^{*}<0
\end{aligned}
$$

where the second equality follows from Eqs. (7) and (8), and the inequality follows from $U^{\prime \prime}(\Pi)<0$. If $\operatorname{Cov}(\tilde{\theta}, \tilde{P}) \leq 0$, Eqs. (6) and (14) imply that $\mathrm{E}(\tilde{P})>C^{\prime}\left(Q^{*}\right)$. It then follows from Eq. (12) and the strict convexity of the cost function that $Q^{*}<Q^{\circ}$, thereby invoking the following proposition.

Proposition 2. Given that the commodity futures and put option contracts are fairly priced, the competitive firm's optimal output level, $Q^{*}$, is less than the benchmark output level, $Q^{\circ}$, if the revenue shock, $\tilde{\theta}$, and the random output price, $\tilde{P}$, are either uncorrelated or negatively correlated.

To see the intuition for Proposition 2, we substitute $P^{f}=\mathrm{E}(\tilde{P})$ and $\Phi=\mathrm{E}[\max (K-$ $\tilde{P}, 0)]$ into Eq. (1) to yield

$$
\begin{aligned}
\tilde{\Pi}^{*}= & \mathrm{E}(\tilde{P}) Q^{*}-C\left(Q^{*}\right)+(\tilde{\theta}-1) \tilde{P} Q^{*}+[\tilde{P}-\mathrm{E}(\tilde{P})]\left(Q^{*}-X^{*}\right) \\
& +\{\mathrm{E}[\max (K-\tilde{P}, 0)]-\max (K-\tilde{P}, 0)\} Y^{*}
\end{aligned}
$$

The prevalence of the revenue shock induces the firm to cut down its output level so as to limit the risk exposure that comes from the third term on the right-hand side of Eq. (15). Taking expectations on both sides of Eq. (15) yields

$$
\mathrm{E}\left(\tilde{\Pi}^{*}\right)=\mathrm{E}(\tilde{P}) Q^{*}-C\left(Q^{*}\right)+\operatorname{Cov}(\tilde{\theta}, \tilde{P}) Q^{*}
$$

If $\tilde{\theta}$ and $\tilde{P}$ are negatively correlated (uncorrelated), the last term on the right-hand side of Eq. (16) is decreasing in (invariant to) the output level, which reinforces (has no effect on) the firm's risk reduction incentive, thereby rendering $Q^{*}<Q^{\circ}$. 


\section{Optimal hedging decisions}

In this section, we examine the firm's optimal hedge position, $\left(X^{*}, Y^{*}\right)$, when the revenue risk prevails. Following Chang and Wong (2003) and Wong (2003, 2013), we assume that

the revenue shock, $\tilde{\theta}$, and the random output price, $\tilde{P}$, are related in the following manner:

$$
\tilde{\theta}=1+\beta[\tilde{P}-\mathrm{E}(\tilde{P})]+\tilde{\varepsilon},
$$

where $\beta$ is a constant, and $\tilde{\varepsilon}$ is a zero-mean random variable independent of $\tilde{P}$. Eq. (17) implies that $\tilde{\theta}$ and $\tilde{P}$ are negatively or positively correlated, depending on whether $\beta$ is negative or positive, respectively. These two random variables are uncorrelated if $\beta=0$.

Kimball $(1990,1993)$ convincingly argues that prudence, i.e., $U^{\prime \prime \prime}(\Pi)>0$, is a reasonable behavioral assumption when decision makers face multiple sources of uncertainty. In contrast to risk aversion that is how much one dislikes uncertainty and would turn away from it if one could, prudence measures the propensity to prepare and forearm oneself under uncertainty. Drèze and Modigliani (1972), Kimball (1990), and Leland (1968) show that prudence is both necessary and sufficient to induce precautionary saving. Furthermore, prudence is implied by decreasing absolute risk aversion, which is instrumental in yielding many intuitively appealing comparative statics under uncertainty (Gollier, 2001). ${ }^{7}$ We as such characterize the firm's optimal hedge position, $\left(X^{*}, Y^{*}\right)$, when its preferences satisfy prudence in the following proposition.

Proposition 3. Given that the competitive firm is prudent and has access to the fairly priced commodity futures and put option contracts for hedging purposes, and that the revenue shock, $\tilde{\theta}$, and the random output price, $\tilde{P}$, are characterized by Eq. (17) with $\beta \leq 0$, the firm's optimal hedge position, $\left(X^{*}, Y^{*}\right)$, consists of an under-hedge, i.e., $X^{*}<Q^{*}$, and a long put option position, i.e., $Y^{*}<0$.

\footnotetext{
${ }^{7}$ As pointed out by Bonilla and Vergara (2013), prudence is consistent with both decreasing and increasing absolute risk aversion.
} 
Proof. See Appendix A.

The intuition for Proposition 3 is as follows. Substituting Eq. (17) into Eq. (15) yields

$$
\begin{aligned}
\tilde{\Pi}^{*}= & \mathrm{E}(\tilde{P}) Q^{*}-C\left(Q^{*}\right)+\beta \tilde{P}[\tilde{P}-\mathrm{E}(\tilde{P})] Q^{*}+\tilde{\varepsilon} \tilde{P} Q^{*}+[\tilde{P}-\mathrm{E}(\tilde{P})]\left(Q^{*}-X^{*}\right) \\
& +\{\mathrm{E}[\max (K-\tilde{P}, 0)]-\max (K-\tilde{P}, 0)\} Y^{*} .
\end{aligned}
$$

If $\beta<(>) 0$, the third term on the right-hand side of Eq. (18) is negatively (positively) correlated with $\tilde{P}$ since $\operatorname{Cov}\left[\beta \tilde{P}[\tilde{P}-\mathrm{E}(\tilde{P}), \tilde{P}]=\beta \mathrm{E}\left\{\tilde{P}[\tilde{P}-\mathrm{E}(\tilde{P})]^{2}\right\}<(>) 0\right.$, which induces the firm to opt for a long (short) futures position. Furthermore, this term is quadratic and concave (convex) in the realized output price, $P$, if $\beta<(>) 0$, which induces the firm to opt for a long (short) put option position to create a convex (concave) payoff that better copes with the associated risk exposure. We refer to this impact on the hedge position as the correlation motive.

The random variable, $\tilde{\varepsilon}$, in the forth term on the right-hand side of Eq. (18) can be interpreted as a zero-mean background risk. The firm, being prudent, has a precautionary motive to shift its profit at date 1 from states with small background risk to states with large background risk so as to mitigate the loss of utility (Eeckhoudt and Schlesinger, 2006). ${ }^{8}$ As is evident from this term, the magnitude of the background risk increases with an increase in the realized value of $\tilde{P}$. The precautionary motive as such calls for a long futures position and a long put option position. If $\beta<(>) 0$, the correlation motive reinforces (counteracts) the precautionary motive. Combining these two motives with the full-hedging motive in the absence of the revenue shock (see Proposition 1), the prudent firm's optimal hedge position consists of an under-hedge, i.e., $X^{*}<Q^{*}$, and a long put option position, i.e., $Y^{*}<0$, if $\beta \leq 0$, and the optimal hedge position becomes ambiguous if $\beta>0$.

\footnotetext{
${ }^{8}$ As shown in Kimball (1990), prudence creates the demand for precautionary saving in that prudent individuals would like to shift more wealth to a later period (i.e., save more) to better cope with the risk arising from uncertain labor income earned at that time. Similar intuition applies to the prudent firm.
} 


\section{An example}

In this section, we construct a reasonable example that has a closed form solution so as to gain more insight into the firm's optimal production and hedging decisions. Suppose that the revenue shock, $\tilde{\theta}$, and the random output price, $\tilde{P}$, are characterized by Eq. (17) such that $\tilde{\varepsilon}$ is a standard normal random variable. Suppose further that $\tilde{P}$ takes on three possible values, $P_{1}, P_{2}$, and $P_{3}$, with $0<P_{1}<P_{2}<P_{3}$. Let $p_{i}$ be the probability that $\tilde{P}=P_{i}$ for $i=1,2$, and 3 , where $0<p_{i}<1$ and $\sum_{i=1}^{3} p_{i}=1$. The expected output price is therefore given by $\mathrm{E}(\tilde{P})=\sum_{i=1}^{3} p_{i} P_{i}$. The put option contracts have a single strike price, $K \in\left(P_{1}, P_{2}\right]$, and the premium per contract, $\Phi=\sum_{i=1}^{3} p_{i} \max \left(K-P_{i}, 0\right)=p_{1}\left(K-P_{1}\right)$.

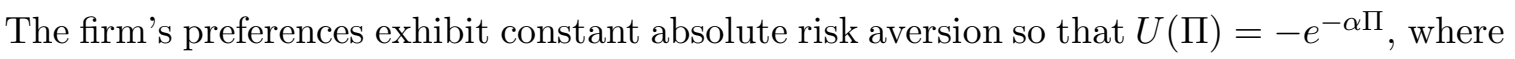
$\alpha>0$ is the constant coefficient of absolute risk aversion.

The first-order conditions for this example are given by

$$
\begin{aligned}
& \mathrm{E}\left\{\sum_{i=1}^{3} p_{i} e^{-\alpha \tilde{\Pi}^{*}\left(P_{i}\right)}\left\{\left\{1+\beta\left[P_{i}-\mathrm{E}(\tilde{P})\right]+\tilde{\varepsilon}\right\} P_{i}-C^{\prime}\left(Q^{*}\right)\right\}\right\}=0, \\
& \mathrm{E}\left\{\sum_{i=1}^{3} p_{i} e^{-\alpha \tilde{\Pi}^{*}\left(P_{i}\right)}\left[\mathrm{E}(\tilde{P})-P_{i}\right]\right\}=0,
\end{aligned}
$$

and

$$
\mathrm{E}\left\{\sum_{i=1}^{3} p_{i} e^{-\alpha \tilde{\Pi}^{*}\left(P_{i}\right)}\left[\Phi-\max \left(K-P_{i}, 0\right)\right]\right\}=0
$$

where $\tilde{\Pi}^{*}\left(P_{i}\right)=\left\{1+\beta\left[P_{i}-\mathrm{E}(\tilde{P})\right]+\tilde{\varepsilon}\right\} P_{i} Q^{*}+\left[\mathrm{E}(\tilde{P})-P_{i}\right] X^{*}+\left[\Phi-\max \left(K-P_{i}, 0\right)\right] Y^{*}-C\left(Q^{*}\right)$. Since $\mathrm{E}(\tilde{P})=\sum_{i=1}^{3} p_{i} P_{i}$ and $\Phi=\sum_{i=1}^{3} p_{i} \max \left(K-P_{i}, 0\right)$, Eqs. (20) and (21) imply that

$$
\begin{aligned}
& e^{-\alpha\left\{P_{1} Q^{*}+\beta\left[P_{1}-\mathrm{E}(\tilde{P})\right] P_{1} Q^{*}+\left[\mathrm{E}(\tilde{P})-P_{1}\right] X^{*}+\left(\Phi-K+P_{1}\right) Y^{*}-C\left(Q^{*}\right)-\alpha\left(P_{1} Q^{*}\right)^{2} / 2\right\}} \\
& =e^{-\alpha\left\{P_{2} Q^{*}+\beta\left[P_{2}-\mathrm{E}(\tilde{P})\right] P_{2} Q^{*}+\left[\mathrm{E}(\tilde{P})-P_{2}\right] X^{*}+\Phi Y^{*}-C\left(Q^{*}\right)-\alpha\left(P_{2} Q^{*}\right)^{2} / 2\right\}} \\
& =e^{-\alpha\left\{P_{3} Q^{*}+\beta\left[P_{3}-\mathrm{E}(\tilde{P})\right] P_{3} Q^{*}+\left[\mathrm{E}(\tilde{P})-P_{3}\right] X^{*}+\Phi Y^{*}-C\left(Q^{*}\right)-\alpha\left(P_{3} Q^{*}\right)^{2} / 2\right\}},
\end{aligned}
$$


which follows from the fact that $\tilde{\varepsilon}$ is a standard normal random variable. Using Eq. (22) and $\mathrm{E}(\tilde{P})=\sum_{i=1}^{3} p_{i} P_{i}$, Eq. (19) reduces to

$$
\mathrm{E}(\tilde{P})-C^{\prime}\left(Q^{*}\right)+\beta \operatorname{Var}(\tilde{P})-\alpha \mathrm{E}\left(\tilde{P}^{2}\right) Q^{*}=0
$$

where $\operatorname{Var}(\tilde{P})$ is the variance of $\tilde{P}$. Define the following constant:

$$
\beta^{\circ}=\frac{\alpha \mathrm{E}\left(\tilde{P}^{2}\right) Q^{\circ}}{\operatorname{Var}(\tilde{P})}>0
$$

where $Q^{\circ}$ is given by Eq. (12). Substituting Eqs. (12) and (24) into Eq. (23) yields

$$
C^{\prime}\left(Q^{\circ}\right)-C^{\prime}\left(Q^{*}\right)+\operatorname{Var}(\tilde{P})\left(\beta-\frac{\beta^{\circ} Q^{*}}{Q^{\circ}}\right)=0
$$

If $\beta>(<) \beta^{\circ}$ but $Q^{*} \leq(\geq) Q^{\circ}$, the strict convexity of $C(Q)$ implies that the left-hand side of Eq. (25) is positive (negative), a contradiction. Hence, it must be true that $Q^{*}>(<) Q^{\circ}$ if $\beta>(<) \beta^{\circ}$. These results are consistent with the findings of Proposition 2 that $Q^{*}<Q^{\circ}$ should $\tilde{P}$ and $\tilde{S}$ be uncorrelated or negatively correlated, i.e., $\beta \leq 0$. Indeed, for all $\beta \in\left(0, \beta^{\circ}\right)$, it remains true that $Q^{*}<Q^{\circ}$. However, if $\beta>\beta^{\circ}$, it must be true that $Q^{*}>Q^{\circ}$, which is a novel result. This is particular the case when the firm is not too risk averse, i.e., when $\alpha$ is close to zero so that the threshold value, $\beta^{\circ}$, is also close to zero. A positive correlation between $\tilde{\theta}$ and $\tilde{P}$ is then likely to be sufficient to induce the firm to produce beyond the optimal output level in the benchmark case wherein the revenue shock is absent.

Solving Eq. (22) yields

$$
X^{*}=Q^{*}+\left\{\beta-\left[\frac{P_{2}+P_{3}}{P_{2}+P_{3}-\mathrm{E}(\tilde{P})}\right] \frac{\alpha Q^{*}}{2}\right\}\left[P_{2}+P_{3}-\mathrm{E}(\tilde{P})\right] Q^{*},
$$

and

$$
Y^{*}=\frac{\left(P_{2}-P_{1}\right)\left(P_{3}-P_{1}\right)}{K-P_{1}}\left(\beta-\frac{\alpha Q^{*}}{2}\right) Q^{*},
$$


where $Q^{*}$ is given by Eq. (23). Since $P_{2}+P_{3}-\mathrm{E}(\tilde{P})=P_{1}+\left(1-P_{2}\right)\left(P_{2}-P_{1}\right)+(1-$ $\left.P_{3}\right)\left(P_{3}-P_{1}\right)>0$, Eqs. (26) and (27) imply that $X^{*}<Q^{*}$ and $Y^{*}<0$ if $\beta \leq 0$, which are consistent with the findings of Proposition 3.

When $\beta=\beta^{\circ}$, it follows from $Q^{*}=Q^{\circ}$ and Eq. (24) that

$$
\begin{aligned}
& \beta^{\circ}-\left[\frac{P_{2}+P_{3}}{P_{2}+P_{3}-\mathrm{E}(\tilde{P})}\right] \frac{\alpha Q^{\circ}}{2} \\
& =\frac{\left\{2\left[P_{2}+P_{3}-\mathrm{E}(\tilde{P})\right] \mathrm{E}\left(\tilde{P}^{2}\right)-\left(P_{2}+P_{3}\right) \operatorname{Var}(\tilde{P})\right\} \alpha Q^{\circ}}{2\left[P_{2}+P_{3}-\mathrm{E}(\tilde{P})\right] \operatorname{Var}(\tilde{P})} .
\end{aligned}
$$

Since $\left[P_{2}+P_{3}-\mathrm{E}(\tilde{P})\right] \mathrm{E}\left(\tilde{P}^{2}\right)=\left(P_{2}+P_{3}\right) \operatorname{Var}(\tilde{P})+\left[p_{1} S_{1}\left(P_{2}+P_{3}-P_{1}\right)+\left(p_{2}+p_{3}\right) P_{2} P_{3}\right] \mathrm{E}(\tilde{P})>$ $\left(P_{2}+P_{3}\right) \operatorname{Var}(\tilde{S})$, Eqs. (26) and (28) imply that $X^{*}>Q^{*}$ when $\beta=\beta^{\circ}$. Differentiating Eq. (23) with respect to $\beta$ yields $\partial Q^{*} / \partial \beta=\operatorname{Var}(\tilde{P}) /\left[C^{\prime \prime}\left(Q^{*}\right)+\alpha \mathrm{E}\left(\tilde{P}^{2}\right)\right]$. It follows that

$$
\begin{aligned}
& \frac{\partial}{\partial \beta}\left\{\beta-\left[\frac{P_{2}+P_{3}}{P_{2}+P_{3}-\mathrm{E}(\tilde{P})}\right] \frac{\alpha Q^{*}}{2}\right\} \\
& =\frac{2\left[P_{2}+P_{3}-\mathrm{E}(\tilde{P})\right]\left[C^{\prime \prime}\left(Q^{*}\right)+\alpha \mathrm{E}\left(\tilde{P}^{2}\right)\right]-\alpha\left(P_{2}+P_{3}\right) \operatorname{Var}(\tilde{P})}{2\left[P_{2}+P_{3}-\mathrm{E}(\tilde{P})\right]\left[C^{\prime \prime}\left(Q^{*}\right)+\alpha \mathrm{E}\left(\tilde{P}^{2}\right)\right]} .
\end{aligned}
$$

Since $C^{\prime \prime}(Q)>0$ and $\left[P_{2}+P_{3}-\mathrm{E}(\tilde{P})\right] \mathrm{E}\left(\tilde{P}^{2}\right)>\left(P_{2}+P_{3}\right) \operatorname{Var}(\tilde{P})$, the right-hand side of Eq. (29) is positive. It then follows from Eqs. (28) and (26) that there exists a threshold value, $\beta^{*} \in\left(0, \beta^{\circ}\right)$, such that $X^{*}<(>) Q^{*}$ if $\beta<(>) \beta^{*}$. Proposition 3 implies that the correlation motive counteracts the precautionary motive whenever $\beta>0$. As $\beta$ increases, the correlation motive gets stronger and soon dominates the precautionary motive once $\beta$ exceeds the threshold, $\beta^{*}$, thereby rendering the optimality of an over-hedge, i.e., $X^{*}>Q^{*}$.

Since $\beta^{*}-\alpha Q^{*} / 2=\alpha \mathrm{E}(\tilde{P}) Q^{*} / 2\left[P_{2}+P_{3}-\mathrm{E}(\tilde{P})\right]>0$, Eq. (27) implies that $Y^{*}>0$ when $\beta=\beta^{*}$. Since $\partial Q^{*} / \partial \beta=\operatorname{Var}(\tilde{P}) /\left[C^{\prime \prime}\left(Q^{*}\right)+\alpha \mathrm{E}\left(\tilde{P}^{2}\right)\right]$, it follows that

$$
\frac{\partial}{\partial \beta}\left(\beta-\frac{\alpha Q^{*}}{2}\right)=\frac{2 C^{\prime \prime}\left(Q^{*}\right)+\alpha\left[\mathrm{E}\left(\tilde{P}^{2}\right)+\mathrm{E}(\tilde{P})^{2}\right] P^{2}}{2\left[C^{\prime \prime}\left(Q^{*}\right)+\alpha \mathrm{E}\left(\tilde{P}^{2}\right)\right]}>0 .
$$

Eqs. (27) and (30) then imply that there exists a threshold value, $\beta^{* *} \in\left(0, \beta^{*}\right)$, such that $Y^{*}<(>) 0$ if $\beta<(>) \beta^{* *}$. For all $\beta \in\left(\beta^{* *}, \beta^{*}\right)$, it must be true that $X^{*}<Q^{*}$ and 
$Y^{*}>0$. Hence, this example suggests that the correlation motive is more profound in affecting the put option position than the precautionary motive, when contrasted to the futures position. Furthermore, even when a full-hedge, i.e., $X^{*}=Q^{*}$, is optimal, which is the case when $\beta=\beta^{*}$, the firm includes a short put option position, i.e., $Y^{*}>0$, in its optimal hedge position, thereby making the full-hedging theorem never hold in this example.

\section{Conclusion}

In this paper, we examine the behavior of a competitive firm under joint output price uncertainty and revenue shock. The firm can trade fairly priced commodity futures and put option contracts for hedging purposes. We show that neither the separation theorem nor the full-hedging theorem holds when the revenue shock prevails. Specifically, if the correlation between the random output price and the revenue shock is non-positive, the firm optimally produces less as compared to the benchmark output level when the revenue shock is absent. If, in addition, the firm's preferences satisfy the reasonable property of prudence (Kimball, 1990, 1993), the prudent firm's optimal hedge position consists of an under-hedge in the futures position and a long put option position. However, if the correlation is sufficiently positive, we construct a canonical example in which the firm optimally produces more, not less, than the benchmark level, and opts for an over-hedge in the futures position and a short put option position. The firm's optimal production and hedging decisions as such depend not only on the risk attitude of the firm, but also on the joint distribution of the random

output price and the revenue shock. The prevalence of revenue risk makes financial and operational hedging act as complements to better cope with multiple sources of uncertainty.

\section{Appendix A. Proof of Proposition 3}

To facilitate the exposition of the proof of Proposition 3, we reformulate program (2) 
as a two-stage optimization problem with the output level fixed at the optimal level, $Q^{*}$. The first stage derives the firm's demand for the commodity futures contracts, $X(Y)$, that maximizes the objective function of program (2) for a given put option position, $Y$. The second stage derives the firm's optimal put option position, $Y^{*}$, that maximizes the objective function of program (2) with $X$ replaced by $X(Y)$. The complete solution to program (2) is, therefore, given by $Y^{*}$ and $X^{*}=X\left(Y^{*}\right)$.

Let $E U$ be the objective function of program (2) with $X$ replaced by $X(Y)$ and $Q$ fixed at $Q^{*}$. Totally differentiating $E U$ with respect to $Y$, using the envelope theorem, and evaluating the resulting equation at $Y=0$ yields

$$
\left.\frac{\mathrm{d} E U}{\mathrm{~d} Y}\right|_{Y=0}=\mathrm{E}\left\{U^{\prime}\left(\tilde{\Pi}^{0}\right)\{\mathrm{E}[\max (K-\tilde{P}, 0)]-\max (K-\tilde{P}, 0)\}\right\}
$$

where $\tilde{\Pi}^{0}=\{1+\beta[\tilde{P}-\mathrm{E}(\tilde{P})]+\tilde{\varepsilon}\} \tilde{P} Q^{*}+[\mathrm{E}(\tilde{P})-\tilde{P}] X(0)-C\left(Q^{*}\right)$. To show that $Y^{*}<0$, it follows from Eq. (8) and the second-order conditions for program (2) that it suffices to show that the right-hand side of Eq. (A.1) is negative.

Since $X(0)$ is the firm's optimal futures position when $Y=0$, it must satisfy the following first-order condition for the first-stage optimization problem:

$$
\int_{\underline{P}}^{\bar{P}} \mathrm{E}\left[U^{\prime}\left(\tilde{\Pi}^{0}\right) \mid P\right][\mathrm{E}(\tilde{P})-P] \mathrm{d} F(P)=0
$$

where $\mathrm{E}(\cdot \mid P)$ is the expectation operator conditional on $\tilde{P}=P$. Partially differentiating $\mathrm{E}\left[U^{\prime}\left(\tilde{\Pi}^{0}\right) \mid P\right]$ twice with respect to $P$ yields

$$
\begin{aligned}
\frac{\partial^{2} \mathrm{E}\left[U^{\prime}\left(\tilde{\Pi}^{0}\right) \mid P\right]}{\partial P^{2}}= & 2 \beta Q^{*} \mathrm{E}\left[U^{\prime \prime}\left(\tilde{\Pi}^{0}\right) \mid P\right] \\
& +\mathrm{E}\left\{U^{\prime \prime \prime}\left(\tilde{\Pi}^{0}\right)\left\{[1+2 \beta P-\beta \mathrm{E}(\tilde{P})+\tilde{\varepsilon}] Q^{*}-X(0)\right\}^{2} \mid P\right\} .
\end{aligned}
$$

Given prudence, i.e., $U^{\prime \prime \prime}(\Pi)>0$, the second term on the right-hand side of Eq. (A.3) is positive. Since $\beta \leq 0$, it follows from $U^{\prime \prime}(\Pi)<0$ that the first term on the right-hand side of Eq. (A.3) is non-negative. Hence, Eq. (A.3) implies that $\mathrm{E}\left[U^{\prime}\left(\tilde{\Pi}^{0}\right) \mid P\right]$ is strictly convex 
in $P$. If $\partial \mathrm{E}\left[U^{\prime}\left(\tilde{\Pi}^{0}\right) \mid \underline{P}\right] / \partial P \geq 0$, then $\partial \mathrm{E}\left[U^{\prime}\left(\tilde{\Pi}^{0}\right) \mid P\right] / \partial P>0$ for all $P>\underline{P}$. In this case, the left-hand side of Eq. (A.2) must be negative, a contradiction. On the other hand, if $\partial \mathrm{E}\left[U^{\prime}\left(\tilde{\Pi}^{0}\right) \mid \bar{P}\right] / \partial P \leq 0$, then $\partial \mathrm{E}\left[U^{\prime}\left(\tilde{\Pi}^{0}\right) \mid P\right] / \partial P<0$ for all $P<\bar{P}$. In this case, the left-hand side of Eq. (A.2) must be positive, a contradiction. Hence, for Eq. (A.2) to hold, it must be true that $\partial \mathrm{E}\left[U^{\prime}\left(\tilde{\Pi}^{0}\right) \mid \underline{P}\right] / \partial P<0$ and $\partial \mathrm{E}\left[U^{\prime}\left(\tilde{\Pi}^{0}\right) \mid \bar{P}\right] / \partial P>0$.

Since $\mathrm{E}\left[U^{\prime}\left(\tilde{\Pi}^{0}\right) \mid P\right]$ is $\mathrm{U}$-shaped in $P$, there must be at least one and at most two distinct points in $(\underline{P}, \bar{P})$ at which $\mathrm{E}\left[U^{\prime}\left(\tilde{\Pi}^{0}\right) \mid P\right]=\mathrm{E}\left[U^{\prime}\left(\tilde{\Pi}^{0}\right)\right]$. Suppose that $\mathrm{E}\left[U^{\prime}\left(\tilde{\Pi}^{0}\right) \mid P\right]=\mathrm{E}\left[U^{\prime}\left(\tilde{\Pi}^{0}\right)\right]$ at only one point, $\hat{P} \in(\underline{P}, \bar{P})$. Rewrite Eq. (A.2) as

$$
\int_{\underline{P}}^{\bar{P}}\left\{\mathrm{E}\left[U^{\prime}\left(\tilde{\Pi}^{0}\right) \mid P\right]-\mathrm{E}\left[U^{\prime}\left(\tilde{\Pi}^{0}\right)\right]\right\}(\hat{P}-P) \mathrm{d} F(P)=0 .
$$

If $\mathrm{E}\left[U^{\prime}\left(\tilde{\Pi}^{0}\right) \mid \underline{P}\right]>\mathrm{E}\left[U^{\prime}\left(\tilde{\Pi}^{0}\right)\right]$, then the left-hand side of Eq. (A.4) must be positive, a contradiction. On the other hand, if $\mathrm{E}\left[U^{\prime}\left(\tilde{\Pi}^{0}\right) \mid \underline{P}\right] \leq \mathrm{E}\left[U^{\prime}\left(\tilde{\Pi}^{0}\right)\right]$, then the left-hand side of Eq. (A.4) must be negative, a contradiction. Hence, it must be true that $\mathrm{E}\left[U^{\prime}\left(\tilde{\Pi}^{0}\right) \mid P\right]=$ $\mathrm{E}\left[U^{\prime}\left(\tilde{\Pi}^{0}\right)\right]$ at exactly two distinct points, $P_{1}$ and $P_{2}$, where $\underline{P}<P_{1}<P_{2}<\bar{P}$.

The right-hand side of Eq. (A.1) can be written as

$$
R(K)=\int_{\underline{P}}^{K}\left\{\mathrm{E}\left[U^{\prime}\left(\tilde{\Pi}^{0}\right)\right]-\mathrm{E}\left[U^{\prime}\left(\tilde{\Pi}^{0}\right) \mid P\right]\right\}(K-P) \mathrm{d} F(P) .
$$

Using Leibniz's rule to differentiate Eq. (A.5) twice with respect to $K$ yields

$$
R^{\prime}(K)=\int_{\underline{P}}^{K}\left\{\mathrm{E}\left[U^{\prime}\left(\tilde{\Pi}^{0}\right)\right]-\mathrm{E}\left[U^{\prime}\left(\tilde{\Pi}^{0}\right) \mid P\right]\right\} \mathrm{d} F(P),
$$

and

$$
R^{\prime \prime}(K)=\left\{\mathrm{E}\left[U^{\prime}\left(\tilde{\Pi}^{0}\right)\right]-\mathrm{E}\left[U^{\prime}\left(\tilde{\Pi}^{0}\right) \mid K\right]\right\} F^{\prime}(K)
$$

Using the fact that $\mathrm{E}\left[U^{\prime}\left(\tilde{\Pi}^{0}\right) \mid P\right]$ has a U-shape and $\mathrm{E}\left[U^{\prime}\left(\tilde{\Pi}^{0}\right) \mid P\right]=\mathrm{E}\left[U^{\prime}\left(\tilde{\Pi}^{0}\right)\right]$ at exactly two distinct points, $P_{1}$ and $P_{2}$, it follows from Eq. (A.7) that $R^{\prime \prime}(K)>0$ if $P_{1}<K<P_{2}$, $R^{\prime \prime}(K)<0$ if $\underline{P}<K<P_{1}$ or if $P_{2}<K<\bar{P}$, and $R^{\prime \prime}(K)=0$ if $K=P_{1}$ or $K=P_{2}$. It 
follows from Eq. (A.6) that $R^{\prime}(\underline{P})=R^{\prime}(\bar{P})=0$. Hence, $R(K)$ attains two local maxima at $K=\underline{P}$ and $K=\bar{P}$. Eq. (A.5) implies that $R(\underline{P})=0$. Also, Eq. (A.5) implies that

$$
R(\bar{P})=\int_{\underline{P}}^{\bar{P}}\left\{\mathrm{E}\left[U^{\prime}\left(\tilde{\Pi}^{0}\right)\right]-\mathrm{E}\left[U^{\prime}\left(\tilde{\Pi}^{0}\right) \mid P\right]\right\}(\bar{P}-P) \mathrm{d} F(P),
$$

which vanishes by Eq. (A.2). In words, $R(K)$ has an inverted bell-shape bounded from above by zero at $K=\underline{P}$ and $K=\bar{P}$. Since $R(K)<0$ for all $K \in(\underline{P}, \bar{P})$, it must be true that $Y^{*}<0$.

To show that $X^{*}<Q^{*}$, there are two mutually exclusive cases of interest: (i) $K \leq \mathrm{E}(\tilde{P})$ and (ii) $K>\mathrm{E}(\tilde{P})$. Consider first the case that $K \leq \mathrm{E}(\tilde{P})$. Evaluating the left-hand side of Eq. (7) at $X^{*}=Q^{*}$, and using Eq. (17) yields

$$
\begin{aligned}
& \int_{\underline{P}}^{\bar{P}} \mathrm{E}\left\{U ^ { \prime } \left\{\bar{\Pi}^{*}+\beta[P-\mathrm{E}(\tilde{P})] P Q^{*}\right.\right. \\
& \left.\left.+[\Phi-\max (K-P, 0)] Y^{*}+\tilde{\varepsilon} P Q^{*}\right\}\right\}[P-\mathrm{E}(\tilde{P})] \mathrm{d} F(P) \\
& =\int_{\underline{P}}^{\bar{P}} \mathrm{E}\left\{U^{\prime}\left\{\bar{\Pi}^{*}+\beta[P-\mathrm{E}(\tilde{P})] P Q^{*}+[\Phi-\max (K-P, 0)] Y^{*}+\tilde{\varepsilon} P Q^{*}\right\}\right. \\
& \left.-U^{\prime}\left\{\bar{\Pi}^{*}+[\Phi-\max (K-P, 0)] Z^{*}+\tilde{\varepsilon} P Q^{*}\right\}\right\}[P-\mathrm{E}(\tilde{P})] \mathrm{d} F(P) \\
& +\int_{\underline{P}}^{\bar{P}} \mathrm{E}\left\{U^{\prime}\left\{\bar{\Pi}^{*}+[\Phi-\max (K-P, 0)] Y^{*}+\tilde{\varepsilon} P Q^{*}\right\}\right. \\
& \left.-U^{\prime}\left(\bar{\Pi}^{*}+\Phi Y^{*}+\tilde{\varepsilon} P Q^{*}\right)\right\}[P-\mathrm{E}(\tilde{P})] \mathrm{d} F(P) \\
& +\int_{\underline{P}}^{\bar{P}} \mathrm{E}\left\{U^{\prime}\left(\bar{\Pi}^{*}+\Phi Y^{*}+\tilde{\varepsilon} P Q^{*}\right)\right. \\
& \left.-U^{\prime}\left[\bar{\Pi}^{*}+\Phi Y^{*}+\tilde{\varepsilon} \mathrm{E}(\tilde{P}) Q^{*}\right]\right\}[P-\mathrm{E}(\tilde{P})] \mathrm{d} F(P),
\end{aligned}
$$

where $\bar{\Pi}^{*}=\mathrm{E}(\tilde{P}) Q^{*}-C\left(Q^{*}\right)$. When $\beta=0$, the first term on the right-hand side of Eq. (A.9) vanishes. On the other hand, when $\beta<0$, it follows from $U^{\prime \prime}(\Pi)<0$ that

$$
U^{\prime}\left\{\bar{\Pi}^{*}+\beta[P-\mathrm{E}(\tilde{P})] P Q^{*}+[\Phi-\max (K-P, 0)] Y^{*}+\varepsilon P Q^{*}\right\}
$$




$$
<(>) U^{\prime}\left\{\bar{\Pi}^{*}+[\Phi-\max (K-P, 0)] Y^{*}+\varepsilon P Q^{*}\right\}
$$

for all $P<(>) \mathrm{E}(\tilde{P})$. Taking expectations on both sides of Eq. (A.10) with respect to the random variable, $\tilde{\varepsilon}$, yields

$$
\begin{aligned}
& \mathrm{E}\left\{U^{\prime}\left\{\bar{\Pi}^{*}+\beta[P-\mathrm{E}(\tilde{P})] P Q^{*}+[\Phi-\max (K-P, 0)] Y^{*}+\tilde{\varepsilon} P Q^{*}\right\}\right\} \\
& <(>) \mathrm{E}\left\{U^{\prime}\left\{\bar{\Pi}^{*}+[\Phi-\max (K-P, 0)] Y^{*}+\tilde{\varepsilon} P Q^{*}\right\}\right\}
\end{aligned}
$$

for all $P<(>) \mathrm{E}(\tilde{P})$. It follows from Eq. (A.11) that the first term on the right-hand side of Eq. (A.9) is positive when $\beta<0$.

Since $Y^{*}<0$, it follows from $U^{\prime \prime}(\Pi)<0$ that

$$
U^{\prime}\left[\bar{\Pi}^{*}+\Phi Y^{*}-\max (K-P, 0) Y^{*}+\varepsilon P Q^{*}\right]<(=) U^{\prime}\left(\bar{\Pi}^{*}+\Phi Y^{*}+\varepsilon P Q^{*}\right)
$$

for all $P<(>) K$. Taking expectations on both sides of Eq. (A.12) with respect to the random variable, $\tilde{\varepsilon}$, yields

$$
\begin{aligned}
& \mathrm{E}\left\{U^{\prime}\left[\bar{\Pi}^{*}+\Phi Y^{*}-\max (K-P, 0) Y^{*}+\tilde{\varepsilon} P Q^{*}\right]\right\} \\
& <(=) \mathrm{E}\left[U^{\prime}\left(\bar{\Pi}^{*}+\Phi Y^{*}+\tilde{\varepsilon} P Q^{*}\right)\right],
\end{aligned}
$$

for all $P<(>) K$. Since $K \leq \mathrm{E}(\tilde{P})$, it must be true that $P-\mathrm{E}(\tilde{P})<0$ whenever $K-P>0$. Hence, it follows from Eq. (A.13) that the second term on the right-hand side of Eq. (A.9) is positive.

Differentiating $\mathrm{E}\left[U^{\prime}\left(\bar{\Pi}^{*}+\Phi Y^{*}+\tilde{\varepsilon} P Q^{*}\right)\right]$ with respect to $P$ yields

$$
\begin{aligned}
\frac{\partial \mathrm{E}\left[U^{\prime}\left(\bar{\Pi}^{*}+\Phi Y^{*}+\tilde{\varepsilon} P Q^{*}\right)\right]}{\partial P} & =\mathrm{E}\left[U^{\prime \prime}\left(\bar{\Pi}^{*}+\Phi Y^{*}+\tilde{\varepsilon} P Q^{*}\right) \tilde{\varepsilon}\right] Q^{*} \\
& =\operatorname{Cov}\left[U^{\prime \prime}\left(\bar{\Pi}^{*}+\Phi Y^{*}+\tilde{\varepsilon} P Q^{*}\right), \tilde{\varepsilon}\right] Q^{*}>0
\end{aligned}
$$


where the inequality follows from $U^{\prime \prime \prime}(\Pi)>0$. Eq. (A.14) implies that the last term on the right-hand side of Eq. (A.9) is positive. Hence, the right-hand side of Eq. (A.9) must be positive. It then follows from Eq. (7) and the second-order conditions for program (2) that $X^{*}<Q^{*}$.

Consider now the case that $K>\mathrm{E}(\tilde{P})$. Write Equation (A.9) as

$$
\begin{aligned}
& \int_{\underline{P}}^{\bar{P}} \mathrm{E}\left\{U ^ { \prime } \left\{\bar{\Pi}^{*}+\beta[P-\mathrm{E}(\tilde{P})] P Q^{*}\right.\right. \\
& \left.\left.+[\Phi-\max (K-P, 0)] Y^{*}+\tilde{\varepsilon} P Q^{*}\right\}\right\}[P-\mathrm{E}(\tilde{P})] \mathrm{d} F(P) \\
& =\int_{\underline{P}}^{\bar{P}} \mathrm{E}\left\{U^{\prime}\left\{\bar{\Pi}^{*}+\beta[P-\mathrm{E}(\tilde{P})] P Q^{*}+[\Phi-\max (K-P, 0)] Y^{*}+\tilde{\varepsilon} P Q^{*}\right\}\right. \\
& \left.-U^{\prime}\left\{\bar{\Pi}^{*}+[\Phi-\max (K-P, 0)] Y^{*}+\tilde{\varepsilon} P Q^{*}\right\}\right\}[P-\mathrm{E}(\tilde{P})] \mathrm{d} F(P) \\
& +\int_{\underline{P}}^{\bar{P}} \mathrm{E}\left\{U^{\prime}\left\{\bar{\Pi}^{*}+[\Phi-\max (K-P, 0)] Y^{*}+\tilde{\varepsilon} P Q^{*}\right\}\right. \\
& \left.-U^{\prime}\left\{\bar{\Pi}^{*}+[\Phi-K+\mathrm{E}(\tilde{P})] Y^{*}+\tilde{\varepsilon} P Q^{*}\right\}\right\}[P-\mathrm{E}(\tilde{P})] \mathrm{d} F(P) \\
& +\int_{\underline{P}}^{\bar{P}} \mathrm{E}\left\{U^{\prime}\left\{\bar{\Pi}^{*}+[\Phi-K+\mathrm{E}(\tilde{P})] Y^{*}+\tilde{\varepsilon} P Q^{*}\right\}\right. \\
& \left.-U^{\prime}\left\{\bar{\Pi}^{*}+[\Phi-K+\mathrm{E}(\tilde{P})] Y^{*}+\tilde{\varepsilon} \mathrm{E}(\tilde{P}) Q^{*}\right\}\right\}[P-\mathrm{E}(\tilde{P})] \mathrm{d} F(P) .
\end{aligned}
$$

The first term on the right-hand side of Eq. (A.9) is zero when $\beta=0$ and is positive when $\beta<0$. Since $Y^{*}<0$, it follows from $U^{\prime \prime}(\Pi)<0$ that

$$
\begin{aligned}
& U^{\prime}\left[\bar{\Pi}^{*}+\Phi Y^{*}-\max (K-P, 0) Y^{*}+\varepsilon P Q^{*}\right] \\
& <(>) U^{\prime}\left\{\bar{\Pi}^{*}+[\Phi-K+\mathrm{E}(\tilde{P})] Y^{*}+\varepsilon P Q^{*}\right\}
\end{aligned}
$$


for all $P<(>) \mathrm{E}(\tilde{P})$. Taking expectations on both sides of Eq. (A.16) with respect to the random variable, $\tilde{\varepsilon}$, yields

$$
\begin{aligned}
& \mathrm{E}\left\{U^{\prime}\left[\bar{\Pi}^{*}+\Phi Y^{*}-\max (K-P, 0) Y^{*}+\tilde{\varepsilon} P Q^{*}\right]\right\} \\
& <(>) \mathrm{E}\left\{U^{\prime}\left\{\bar{\Pi}^{*}+[\Phi-K+\mathrm{E}(\tilde{P})] Y^{*}+\tilde{\varepsilon} P Q^{*}\right\}\right\}
\end{aligned}
$$

for all $P<(>) \mathrm{E}(\tilde{P})$. Hence, it follows from Eq. (A.17) that the second term on the right-hand side of Eq. (A.15) is positive. Using Eq. (A.14), it can be easily verified that $\mathrm{E}\left\{U^{\prime}\left\{\bar{\Pi}^{*}+[\Phi-K+\mathrm{E}(\tilde{P})] Y^{*}+\tilde{\varepsilon} P Q^{*}\right\}\right\}$ is increasing in $P$, thereby implying that the last term on the right-hand side of Eq. (A.15) is positive. Hence, the right-hand side of Eq. (A.15) must be positive. It then follows from Eq. (7) and the second-order conditions for program (2) that $X^{*}<Q^{*}$.

\section{References}

Adam-Müller, A. F. A. (1997). Export and hedging decisions under revenue and exchange rate risk: a note. European Economic Review, 41, 1421-1426.

Ahn, D.-H., Boudoukh, J., Richardson, M., \& Whitelaw, R. F. (1999). Optimal risk management using options. Journal of Finance, 54, 359-375.

Batra, R. N., \& Ullah, A. (1974). Competitive firm and the theory of input demand under price uncertainty. Journal of Political Economy, 82, 537-548.

Battermann, H. L., Braulke, M., Broll, U., \& Schimmelpfennig, J. (2000). The preferred hedge instrument. Economics Letters, 66, 85-91.

Bonilla, C. A., \& Vergara, M. (2013). Credit rationing or entrepreneurial risk aversion? A comment. Economics Letters, 120, 329-331.

Broll, U., \& Wong, K. P. (2013). The firm under uncertainty: Real and financial decisions. Decisions in Economics and Finance, 36, 125-136. 
Chang, E. C., \& Wong, K. P. (2003). Cross-hedging with currency options and futures. Journal of Financial and Quantitative Analysis, 38, 555-574.

Chavas, J.-P. (1985). On the theory of the competitive firm under uncertainty when initial wealth is random. Southern Economic Journal, 51, 818-827.

Danthine, J.-P. (1978). Information, futures prices, and stabilizing speculation. Journal of Economic Theory, 17, 79-98.

Drèze, J. H., \& Modigliani, F. (1972). Consumption decisions under uncertainty. Journal of Economic Theory, 5, 308-335.

Eeckhoudt, L., \& Schlesinger, H. (2006). Putting risk in its proper place. American Economic Review, 96, 280-289.

Feder, G., Just, R. E., \& Schmitz, A. (1980). Futures markets and the theory of the firm under price uncertainty. Quarterly Journal of Economics, 94, 317-328.

Froot, K. A., Scharfstein, D. S., \& Stein, J. C. (1993). Risk management: Coordinating corporate investment and financing policies. Journal of Finance, 48, 1629-1658.

Gollier, C. (2001). The Economics of Risk and Time. Cambridge, MA: MIT Press.

Holthausen, D. M. (1979). Hedging and the competitive firm under price uncertainty. American Economic Review, 69, 989-995.

Kimball, M. S. (1990). Precautionary saving in the small and in the large. Econometrica, $58,53-73$.

Kimball, M. S. (1993). Standard risk aversion. Econometrica, 61, 589-611.

Lapan, H., Moschini, G., \& Hanson, S. D. (1991). Production, hedging, and speculative decisions with options and futures markets. American Journal of Agricultural Economics, $73,66-74$.

Leland, H. E. (1968). Saving and uncertainty: The precautionary demand for saving. Quarterly Journal of Economics, 82, 465-473. 
Mossin, J. (1968). Aspects of rational insurance purchasing. Journal of Political Economy, $76,553-568$.

Sandmo, A. (1971). On the theory of the competitive firm under price uncertainty. American Economic Review, 61, 65-73.

Smith, C. W., \& Stulz, R. M. (1985). The determinants of firms' hedging policies. Journal of Financial and Quantitative Analysis, 20, 391-405.

Stulz, R. M. (1984). Optimal hedging policies. Journal of Financial and Quantitative Analysis, 19, 127-140.

Stulz, R. M. (1990). Managerial discretion and optimal financial policies. Journal of Financial Economics, 26, 3-27.

Tufano, P. (1996). Who manages risk? An empirical examination of risk management practices in the gold mining industry. Journal of Finance, 51, 1097-1137.

Viaene, J.-M., \& Zilcha, I. (1998). The behavior of competitive exporting firms under multiple uncertainty. International Economic Review, 39, 591-609.

Wong, K. P. (1996). Background risk and the theory of the competitive firm under uncertainty. Bulletin of Economic Research, 48, 241-251.

Wong, K. P. (2003). Currency hedging with options and futures. European Economic Review, 47, 833-839.

Wong, K. P. (2013). Export and hedging decisions under correlated revenue and exchange rate risk. Bulletin of Economic Research (DOI: 10.1111/boer.12016).

Wong, K. P. (2014). Hedging and the competitive firm under correlated price and background risk. Decisions in Economics and Finance, 37, 329-340.

Wong, K. P. (2015). Ambiguity and the value of hedging. Journal of Futures Markets, 35, in press. 